\title{
3 Años 90: cambio de lógica y concentración
}

En su texto clásico sobre el boom, Ángel Rama distingue entre editoriales “comerciales” y editoriales "culturales”. Según su propuesta -aunque bien se podría discutir o establecer mayores precisiones-, las segundas fueron determinantes para la insólita circulación internacional de literatura latinoamericana a nivel mundial de aquel momento. Su argumento apuntaba a cuestionar una caracterización del boom únicamente en términos de mercado y a exaltar el valor literario de los textos que lo apuntalan:

Al designar a las editoriales que acompañaron a la nueva narrativa como "culturales" pretendo realzar una tendencia que en ocasiones manifestaron en detrimento de la normal tendencia comercial de una empresa, llevándolas a publicar libros que previsiblemente tendrían poco público pero cuya calidad artística les hacía correr el riesgo. Esas editoriales fueron dirigidas o asesoradas por equipos intelectuales que manifestaron responsabilidad cultural y nada lo muestra mejor que sus colecciones de poesía. Propiciaron la publicación de obras nuevas y difíciles, interpretando sin duda las demandas iniciales de un público asimismo nuevo, mejor preparado, y más exigente, pero lo hicieron, pensando en el desarrollo de una literatura más que en la contabilidad de la empresa.

("El boom...” 67)

Estas editoriales eran, entre otras y acá también siguiendo a Rama, Losada, Emecé y Sudamericana, de Argentina; el Fondo de Cultura Económica, Era y Joaquín Mortiz, de México; Nascimento y Zigzag, de Chile; Alfa y Arca, de Uruguay; Monte Ávila, de Venezuela; y, fundamentalmente, Seix Barral, de Barcelona. Si bien quizás resultaría conveniente distinguir el impacto que pudieron tener las editoriales con sede en América Latina del que en efecto tuvo Seix Barral $u$ otras establecidas en Barcelona, lo cierto es que la lógica que dominaba la política de edición por aquel entonces, con un editor "cultural" a la cabeza, quien, a su vez, depositaba su confianza en el equipo de intelectuales que directa o indirectamente lo asesoraba -como el grupo de "los sabios" a Carlos Barral- ha quedado en el pasado como símbolo de una época. Sobre estos aspectos ya informaba Ángel Rama a comienzos de los 80; sostenía que crear un público y un mercado internacionales para literatura latinoamericana exigente,

había de implicar una coordinación de esfuerzos con las editoriales europeas en una suerte de "pool" dentro del cual Seix Barral procuró exitosamente representar no sólo a España sino a todo el orbe de la lengua española (los premios internacionales fueron su manifestación externa) pero tanto la fragilidad de las editoras culturales españolas como la irrupción en España de las multinacionales (sobre todo alemanas) en un proceso de concentración de capital habrían de fijar los límites del esfuerzo y conducir al mismo fracaso que se había registrado en América Latina. Las editoras culturales cedieron su autonomía ante los bancos 
que compraron su paquete accionario o ante las multinacionales vinculadas a esos bancos, estableciendo las condiciones de un nuevo mercado editor y librero. (71-72)

Ángel Rama no llegará a presenciar las verdaderas dimensiones del proceso de concentración, pues es recién a comienzos de los años 90 cuando se dan las condiciones históricas necesarias para que los grandes grupos multimedios desplieguen su política más agresiva de expansión al mismo tiempo que las editoriales "culturales" que, en los años 60, habían logrado tener una cierta influencia en la conformación de hábitos de lectura del público internacional desaparezcan o sean anexadas a los conglomerados. En 1982, Planeta se hace con Seix Barral, en 1985 con Joaquín Mortiz y en el 2002 con Emecé. Sudamericana pasa a manos del grupo Bertelsmann en el 2001. El grupo Educaria absorbe Zigzag, y Cal y Canto, Arca para reorientarlas al mercado de textos escolares. En breve, de las editoriales mencionadas por Rama, las que no fueron incorporadas a los grandes grupos transnacionales, o desaparecieron por completo o redefinieron tanto su perfil que ya no pueden ser consideradas bajo la misma categoría que en los años 80 . Esta evolución, no obstante, no es meramente nominal o administrativa; por el contrario, acarrea una serie de transformaciones decisivas en la lógica que va a dominar la producción y recepción de literatura, particularmente a nivel internacional. Revisemos algunos aspectos generales.

Como ya he adelantado, el enfoque de Pierre Bourdieu nos permite entender la producción de literatura como un complejo proceso donde directa o indirectamente intervienen muchos más actores que el mítico "autor" de los románticos. También, gracias a sus aportes, podemos pensar el campo literario como un sistema donde cada uno de los elementos se ve conducido -determinado- a desempeñar las funciones que la estructura general le asigna, es decir, que los condicionamientos del campo regulan el comportamiento de los actores según la posición que estos ocupen.

Con Bourdieu, sin embargo, puede ocurrir el mismo problema que en casos se registra con otros fundadores de discursividad, como, por ejemplo, Marx o Foucault: los marxistas, los foucaultianos y, dado el caso, bourdieuanos cuando asumen una postura ortodoxa o inflexible. Este mecanismo de aplicación ciega resulta aún más conflictivo cuando se activa un proceso de transferencia mecánico destinado a exportar fórmulas acuñadas en Europa para pensar Europa a tramas socioculturales sensiblemente diferentes. Descartemos, por supuesto, que con esta afirmación se estaría abogando por algún tipo de modelo nativista adánico, simplemente lo que trata de destacar es que los grandes sistemas de pensamiento son válidos, justamente, porque son reajustables de acuerdo con las variables particulares que estemos manejando para el caso específico. Son reajustables y también exigen ser reajustados. 
Bourdieu desarrolló su modelo estructuralista a partir de un caso concreto al que no dejaba de hacer referencia: la Francia decimonónica de Gustave Flaubert. Su teoría se proyecta constante y explícitamente hacia la configuración que poseía ese campo literario específico -y nacional-, pero también deberíamos leer en sus fórmulas marcas -ciertamente menos palpables- de lo que fueron las condiciones históricas que regularon su propia producción: una Francia dominada por el imaginario del $68 \mathrm{y}$ tensionada por los discursos aglutinadores que partían aguas durante la, así denominada, Guerra Fría. Creo que el modelo de Bourdieu conserva una vigencia general, pero resulta conveniente tener presente, particularmente si lo que está en consideración son fenómenos de alcance mundial, que desde 1990 en adelante hemos ingresado en una fase histórica con una serie de implicancias, incluso en lo que atañe a la lógica dominante en lo que, para denominarlo de algún modo, puede ser considerado el campo literario internacional. Así, de acuerdo con Andreas Huyssen, por ejemplo, "the trend to transnational economic networking accelerated significantly after the fall of the Berlin Wall in 1989, the collapse of the Soviet Union, and the opening up of China to capitalist investment" (9).

Según afirmaba Bourdieu todavía en los años 80 ,

El campo literario o artístico es, en todo momento, la escena de una lucha entre los dos principios de jerarquización: el principio heterónomo, favorable a los que dominan el campo económica y políticamente (p. ej., el "arte burgués”), y el principio autónomo (p. ej., el "arte por el arte"), que sus defensores más desprovistos de todo capital específico tienden a identificar con el grado de independencia con respecto a la economía, haciendo del fracaso temporal un signo de transacción con la vida mundana.

(“El campo..." 18)

El campo literario, así, en una definición ontológica no localizada -es decir, "en todo momento"-, se presenta como el escenario de una batalla entre todos los actores "interesados" -en el sentido de tener intereses y no en el romántico- en la literatura. La lógica más heterónoma del campo, a su vez, se puede concebir como una fuerza centrífuga que tiende a alejar al campo de su eje y proyectarlo sobre funciones ancilares, mientras que la lógica más autónoma sería una fuerza opuesta -centrípeta- que orienta la producción estética hacia sí misma.

Ahora, la pregunta es si esta caracterización permite aplicaciones más allá de los contextos que Bourdieu tenía en mente y desde el cual estaba pensando. La reciente evolución histórica mundial ha sido lo suficientemente significativa como para que la pregunta no sea respondida con una nota al pie. Ubiquémonos, pues, a mediados de la segunda década del siglo XXI donde fórmulas como la del "arte por el arte" o la del "compromiso" sartreano suenan, si no ridículas, al menos marcadamente anacrónicas. Gisèle Sapiro, como es sabido, discípula directa de Bourdieu, examina actualmente los factores culturales, políticos, 
sociales y económicos que influyen en la circulación internacional de literatura, y anota

Economic considerations are thus involved in the production and circulation of books and in many cases prevail over other considerations. This is especially true in countries where the book market is liberalized. In the United States and the United Kingdom, cultural goods appear primarily as commercial products that must obey the law of profitability. [...] In the era of globalization, the publishing industry has been increasingly dominated by large conglomerates that impose fierce criteria of commercial profitability and operation to the detriment of literary and intellectual criteria. (87)

Estos conglomerados multimedios, que son pocos -cada vez menos- y que poseen mucho, son actores que hace 30 años, cuando Bourdieu ${ }^{1}$ o Rama analizaban los atributos del campo y la lógica editorial, apenas comenzaban a cobrar forma material. Su aparición y/o consolidación durante los años 90 ha alterado profundamente la lógica del campo literario, pensado en términos generales y también abstractos.

Ahora, afinemos un poco la mira, tomemos distancia del mundo anglófono que comenta Sapiro y observemos América Latina y las tramas que proyectan su literatura hacia el mundo y que enlazan su dinámica productiva con otras regiones. La bibliografía al respecto suele ser concluyente (Sarlo, Yúdice, Batto, Escalante Gonzalbo): hacia comienzos de los 90 la industria editorial latinoamericana comienza a ser aceleradamente colonizada por los conglomerados multimedios transnacionales de origen europeo: particularmente, por los grupos Planeta, español, Santillana, español, y Bertelsmann, alemán. Son grupos con presencia en todas las ramas de la industria cultural: en la televisión, en la música, en la radio, en la prensa escrita y también en la literatura, tanto en el rubro más estrictamente editorial como en la distribución y en las bocas de ventas. De este modo, establecen un circuito y una lógica de gestión donde

1 En su texto de 1999, “Una revolución conservadora en la edición”, Bourdieu ya advertía una "transformación profunda del campo editorial” que podría estar implicando, incluso en el dominio nacional que a él le interesa, una resolución de la tensión entre el polo autónomo y el heterónomo, y un consecuente quiebre ontológico en la entidad del campo, en favor del segundo: "Estos acontecimientos comerciales convertidos en acontecimientos literarios (cuyo paradigma es el éxito dado a Houellebecq) constituyen, en su ambigüedad misma, una de las manifestaciones más significativas y más sutilmente enmascaradas de una transformación profunda del campo editorial. Constituyen la obra de una nueva categoría de agentes económico-literarios que, valiéndose de la familiaridad con el estado anterior del campo literario, más autónomo, pueden imitar de manera sincera o cínica, a los modelos de vanguardia en un nuevo estado del campo, caracterizado por el reforzamiento de la presión de las coacciones económicas y de la atracción ejercida por el polo comercial” (253). 
cada una de las ramificaciones opera en función de los beneficios económicos del todo. Como apunta Escalante Gonzalbo,

La dirección del grupo impone los criterios generales de operación: línea editorial, tirajes, comercialización, tasa de ganancia, pero en las librerías, en las reseñas, de cara al público, prácticamente no aparece la imagen de la gran corporación, sino la de una gran cantidad de sellos distintos, cada uno con su personalidad (al menos, un simulacro más o menos convincente de personalidad). (206)

De este modo, unos pocos grupos - para el caso de América Latina actualmente casi en exclusivo Bertelsmann y Planeta- imponen su lógica economicista para la administración de la literatura y el control de los flujos internacionales. Después del "momento clásico" -el de editores "culturales" como Carlos Barral- ingresamos, como sugiere Escalante Gonzalbo, en el "momento monopólico" (200): uno que, junto con la creciente concentración, se caracteriza por priorizar el criterio de rentabilidad económica a cualquier otro, incluido el del valor literario que todavía estaba en vigencia cuando, por ejemplo, Sudamericana publicaba Rayuela (1963) o Cien años de soledad (1967). Al respecto y en conformidad tanto con Daniel Link como con el epígrafe de Pascale Casanova que introduce este capítulo, me interesa poner de relieve el sensible corrimiento en lo que va de la incipiente literatura latinoamericana mundial que emerge en los años 60, la que toma la forma del boom, y la que comienza a diseñarse desde los años 90 en adelante:

De modo que hay que destacar esa diferencia dramática entre los años sesenta y los noventa, en lo que a las relaciones entre mercado y literatura se refiere: los años sesenta no tenían una teoría neoliberal de los mercados (al menos en América Latina) y el boom, siendo como fue un efecto de la industria editorial, tuvo también una dimensión política e ideológica impensable en el presente: tal es el grado de reificación al que la producción literaria ha llegado. ${ }^{2}$

(Link 18)

2 El mismo fenómeno observa José Ignacio Padilla cuando anota que "Atrás quedaron también los años sesenta, un momento en el que confluyeron un campo cultural/literario consolidado y grandes proyectos editoriales" ("Independientes" 244). Personalmente, creo que la mejor manera de distinguir entre el proceso de internacionalización de la novela latinoamericana durante los años 60 y la producción deliberada de literatura latinoamericana para el mundo a partir de los años 90 es que, en la primera fase, la literatura todavía seguía una agenda propia, concentrada al mismo tiempo en la exploración y diseño de una identidad latinoamericana como en la asunción de ciertos desafíos formales. En el segundo período, por el contrario, la literatura con vocación mundial habría resignado su propio programa para aceptar como premisa máxima las demandas del mercado internacional. Farabeuf (1965) o Paradiso (1966) se podría postular- devienen mundiales a pesar de la industria editorial internacional. El viajero del siglo (2009), gracias a ella. 
Dicho en otros términos, el "dramático" desplazamiento radica en que desde entonces el campo literario no solo pasa a estar controlado por fuerzas transnacionales, sino que estas fuerzas responden unívocamente a la lógica heterónoma. Lo cual también significa que el campo literario de Bourdieu pensado hoy y -si es que resulta posible el traslado- pensado a escala mundial se encuentra de tal suerte dominado por este actor -encarnado ejemplarmente por lo gerentes de ventas- que la crítica académica o el activismo cultural muy raramente pueden influir en la producción y puesta en circulación de literatura. Sin duda el campo literario es, en principio, algo más que el mercado del libro, pero la zona heterónoma, la que concibe a la literatura como herramienta para fines que la exceden y la desplazan hacia otros dominios, ha conseguido imponer de tal modo su lógica al conjunto que una asimilación entre mercado del libro y campo literario, al menos a escala internacional, no resulta tan equívoco. ${ }^{3}$ Esto supone que tanto el periodismo como la crítica literaria académica o los mismos escritores reproducen en muchos casos las convenciones de producción y lectura alentadas y, finalmente, impuestas por los grandes grupos. Los casos de excepción, que por supuesto los hay y que -como veremos- corresponde incluirlos en el examen, raramente llegan a tener un impacto considerable en el escenario "mayor" de la literatura, esto es, en el de la nueva literatura mundial.

Observemos un caso concreto tanto en términos materiales como materialistas. Sudamericana -como ya he adelantado- fue una editorial argentina histórica que supo dar a conocer a escritores como Julio Cortázar y Gabriel García Márquez. Había acumulado peso simbólico, y durante los años 90 estuvo a cargo de Luis Chitarroni, un escritor y editor literario muy respetado por la zona más especializada del campo literario nacional. En el 2001 fue, como otras editoriales nacionales con cierto prestigio, absorbida por un grupo transnacional, en este caso, el grupo Bertelsmann asociado con Mondadori, en aquel momento todavía en manos de Silvio Berlusconi, y Random House. Luis Chitarroni, por su parte, renunció poco tiempo después con el argumento de que, en tanto editor general, ya no veía que cumpliera ninguna función porque

3 Es Itamar Even-Zohar quien, de manera generalizada, más ha acentuado la identificación entre mercado, por un lado, y campo o sistema, por el otro: "Be it a literary salon, a royal court, or an open medieval market-place, where producers actually try to sell their products, or through agents, such as literary critics, editors, teachers, and other promoters, in the absence of a market there is no socio-cultural space where any aspect of the literary activities can gain any ground. Moreover, a restricted market naturally restricts the possibilities of literature to evolve as a socio-cultural activity. So proliferating the market lies in the very interest of the literary system" (39). 
de ningún modo podía influir en las decisiones de publicación: desde la transferencia en el 2001 se introdujo el criterio de publicar exclusivamente libros que a priori garantizaran ventas y que, por lo demás, estaban lejos de sus conceptos estéticos. Hoy en día Sudamericana no existe más como tal, su infraestructura productiva sirve al sello Penguin Random House-Mondadori/Alfaguara. Consideremos este dato: en el año 1999, cuando Bertelsmann ya había comenzado con el proceso de absorción de Sudamericana, Olaf Mantel, el gerente a cargo de la inversión en Argentina, anunció que, desde entonces, Sudamericana no publicaría más a autores argentinos que vendieran menos de 3000 ejemplares (Ruiz 26). Es posible observar en este proceso y leer en estas palabras, al margen de lo problemático que se pueda encontrar, una manifestación material y explícita de cómo la lógica heterónoma (encarnada, en este caso, por un gerente menor de Bertelsmann) del campo se ha impuesto sobre la lógica autónoma (un editor literario como Luis Chitarroni) de manera tan absoluta que esta última se ha visto obligada a ceder su lugar. De manera tan determinante -y esto es finalmente lo que está en juego- que el concepto de "valor literario", según lo concibió la modernidad europea, ha quedado - pareciera- abolido.

Este caso reproduce el más célebre de André Schiffrin y, al mismo tiempo, permite sostener que la lógica que se va a ir imponiendo de manera contundente durante los años 90 en el campo hispánico sigue pautas ya avanzadas en el anglófono. Actualmente, Bertelsmann es el grupo con mayor dominio de mercado a nivel mundial. En 1998, antes de adquirir Sudamericana en Argentina, se había hecho con el control de Random House en EE.UU. Esta editorial, por su parte, ya había absorbido Pantheon Books en una fase temprana, en 1961, poco después de haber comenzado a operar en la bolsa de New York. ${ }^{4}$ Durante casi treinta años, sin embargo, André Schiffrin, en tanto editor general, pudo controlar los criterios de edición de acuerdo con una impronta "culturalista". Dio a conocer, entre otros, a Günter Grass, a Michel Foucault y a Marguerite Duras. En 1980 Samuel Irving Newhouse Jr. adquirió la editorial y, desde entonces, la presión ejercida sobre Schiffrin para incrementar las ganancias fue en aumento. En 1990, después de años de tensión entre la lógica heterónoma y la autónoma, Schiffrin fue conducido a renunciar a su cargo y a ceder, con ello, el dominio absoluto de los criterios de edición a la lógica economicista. Para ese entonces, Alberto Vitale, proveniente del mundo de las finanzas, había asumido el control general de Random House en calidad de gerente general (Schiffrin Business...).

4 Según Escalante Gonzalbo (201), 1959 es el año inaugural del "momento monopólico", debido, precisamente, a que en ese momento comienzan por primera vez a cotizarse en la bolsa de New York acciones de una editorial, las de Random House. 
Estos dos casos ilustran de modo resumido la evolución del escenario mundial de la industria editorial. Después de algunas transacciones intermedias, en la que hombres netamente de negocios como Silvio Berlusconi, Samuel Irving Newhouse Jr., Olaf Mantel y Alberto Vitale ganan terreno en el campo literario sobre figuras como André Schiffrin o Luis Chitarroni, la matriz productiva queda, finalmente, acaparada por completo por el sello transnacional Bertelsmann. Estamos, sin duda, en el "momento monopólico", pero también bajo la hegemonía de una lógica que Schiffrin (L'édition...) caracterizó como la de "la edición sin editores”. Bajo esta lógica, los gerentes de ventas determinan las políticas editoriales a partir de premisas acuñadas, fundamental si no exclusivamente, en el mundo de los negocios. La zona más autónoma del campo queda desplazada del gran escenario y la literatura, así, pasa a ser lo que quienes controlan los grandes canales de producción y puesta en circulación, directa o indirectamente, determinan que debe ser. Para ello, los gerentes de la edición activan campañas publicitarias, encargan reseñas en los medios vinculados y sobrecargan la mesa de novedades de las cadenas de librerías y las góndolas de los supermercados con el título de ocasión. Es por esto que José Manuel Lara Hernández, el fundador del grupo Planeta, podía afirmar -diría que realmente sin ironía- que "Saber de literatura es malo para un editor; yo soy capaz de convertir un libro con las páginas en blanco en un auténtico éxito de ventas" (Moret 121). Lo cual en cierto modo equivaldría a decir que "las editoriales dirigidas o asesoradas por equipos intelectuales que manifestaban responsabilidad cultural”, esas de las que hablaba Ángel Rama a comienzos de los 80 y que pudieron haber alentado el boom, se han extinguido por idealistas y que el "valor literario", según fue concebido por cierta vertiente ideológica hegemónica de la modernidad occidental, desde Immanuel Kant pasando por Gustave Flaubert hasta Theodor Adorno, no era más que una categoría histórica destinada a agotarse en la medida en que el capitalismo evolucionara hacia una fase más desarrollada.

Voy a retomar el tema de la concentración en el apartado II.2., pero, ¿es realmente así? ¿Han desaparecido por completo la autonomía y el valor literario? Creo, con Ignacio Sánchez Prado, que una perspectiva derrotista carece de sustento. Ni la fase de la autonomía fue una edad dorada, ni el escenario actual -como voy a intentar demostrar en el próximo apartado- puede reducirse al dominado por los grandes grupos multimedios. Sánchez Prado argumenta que

En la medida en que en los últimos treinta años las lógicas de mercado literario, evaluadas con suspicacia por Rama y sus contemporáneos, se han exacerbado en direcciones impredecibles, un modelo basado en la distinción entre una literatura estéticamente autónoma, por un lado, y un mercado que canibaliza sus producciones y las introduce a la lógica de circulación económica, por otro, es inoperante.

("Más allá..." 19) 
La afirmación, a mi entender, es válida en la medida que se refine la óptica de análisis y no necesariamente mediante postulados de los estudios culturales, como sugiere Sánchez Prado. Creo, en efecto, que el orden analizado por Rama en su momento ha cedido terreno a uno regido, fundamentalmente, por leyes de mercado. Distinguir entre literatura de mercado y literatura "exigente" o "culta" resulta, en este sentido, inoperante. Pero esto vale, en primer término, para el ámbito en el que se desenvolvió el boom, esto es, el mercado literario internacional y el campo correspondiente. Considero que la concentración editorial a escala mundial sí ha determinado que, al menos a ese nivel, haya quedado neutralizada, aunque sea temporalmente, la lógica autónoma del campo. Lo cual, de todos modos, en principio no debería ser evaluado más que en términos objetivos: como lo propone Escalante Gonzalbo, de un "momento clásico”, en el que representantes de una élite cultural podían elegir con (sus) criterios estéticos qué entraba en circulación internacional, hemos pasado al “momento monopólico", en el que una élite económica impone sus criterios a todo el campo. El circuito completo de producción, puesta en circulación y evaluación de la literatura va a aparecer, así, condicionado directa o indirectamente por la lógica mercantilista, lo cual no forzosamente implica censura ideológica, sino, mucho antes, que el criterio de selección es unilateral y se aplica a todos los productos de la misma manera:

No hace falta que nadie tenga la intención de censurar la libre expresión ni de imponer una doctrina, aunque podría hacerse perfectamente con esa estructura, sería incluso fácil: se hace algo más y menos, que es imponer una lógica al campo cultural. Se publica a Milton Friedman lo mismo que a Noam Chomsky, Susan Sontag o Thomas Frank, el único criterio que cuenta -y ese es el meollo de la transformación- es el índice de ventas.

(Escalante Gonzalbo 210)

El punto es que este nuevo modo de gestión de la literatura no debe ser confundido con un proceso de democratización favorable a la circulación irrestricta o "menos" restricta de productos literarios. Antes, habría que pensar que los criterios de selección y jerarquización se han transformado: ya no los establecen -o siquiera los negocian- "los sabios" sino "los gerentes", ya no se resuelven en la tensión entre la zona autónoma del campo y la zona heterónoma sino que esta última hace valer los suyos para toda la estructura. Por eso, reclama Beatriz Sarlo, "no es indispensable celebrar la decadencia de la autoridad de los artistas e intelectuales cuando ella se produce por el ascenso de los gerentes de la industria cultural" (167). Y si esta evolución, acaso, es constatable en general, es el escenario internacional -donde ejercen su mayor influjo los grupos monopólicos y donde el factor dinero deviene crucial para el funcionamiento de la maquinaria- el territorio que más se va a ver condicionado. La lógica de mercado a este nivel va a devenir 
inapelable y va a ser la principal, si no la única, autorizada a seleccionar los productos que entran en circulación más allá de las fronteras nacionales. Dice Sarlo, y la imagen es particularmente oportuna, que "El mercado opera como consulado del gusto: unos productos circulan con visados preferenciales, otros son favorecidos por políticas proteccionistas, unos pocos son desterrados, una cantidad considerable tiene problemas serios de ingreso" (167). Así, el criterio determinante para decidir a priori la suerte de la circulación internacional de un libro va a ser en primer lugar el del potencial de ventas, es decir, el valor económico y no ya -aunque, dado el caso, después de una evaluación crítica a posteriori se lo pueda constatar en algún caso-, el valor literario que supieron enarbolar en su momento las "editoriales culturales” de Rama. Este último, se podría argumentar, va a operar como variable secundaria o factor residual, no prioritario.

Todo esto, formulado en otros términos y para retomar, lo que en última instancia viene a sugerir es que la nueva literatura mundial, controlada por gerentes de ventas y agentes literarios, es, fundamentalmente y en primer lugar, un objeto de consumo destinado ante todo a producir beneficios económicos, lo cual, sin embargo, todavía no estaría diciendo nada de la literatura a secas. Y - como voy a intentar presentar de manera desglosada en el siguiente capítulo- es posible explicar en términos muy simples por qué esto es así: la puesta en circulación de literatura a nivel mundial implica un proceso de agregado de valor que exige, de modo insoslayable, la mediación de actores (scouts, editores, agentes, traductores, periodistas) que no pueden dejar de cobrar sus dividendos. Hacer que un texto de cualquier origen llegue a un público internacional requiere, al menos, el pago de anticipos, de honorarios de traducción y de participación de los agentes. Un costo económico que no se puede evitar y que debe ser recuperado para que el proyecto económico/cultural que impulsa la publicación pueda seguir funcionando. El índice de ventas, a falta de mejores herramientas, es el indicador que permite evaluar en qué medida un título puede, o no, garantizar el sano funcionamiento de la estructura productiva. Esa "lógica", por otra parte, opera como el repertorio de reglas básicas que deben ser aceptadas para participar del "juego" de la literatura en el escenario mundial.

Volvamos ahora al caso de Luis Chitarroni y a los ajetreos locales. Unos años después de haber abandonado Sudamericana/Bertelsmann, Chitarroni reaparece en el campo nuevamente como editor, ahora, a cargo de una pequeña editorial independiente de nombre La bestia equilátera cuyo catálogo -que incluye a César Aira, Arnaldo Calveyra, Daniel Guebel y también a narradores estadounidenses como Kurt Vonnegut- deja entrever claramente las preferencias de su editor. Algo similar, por su parte, ocurre con el tránsito de André 
Schiffrin a la edición independiente y sin fines de lucro con la hoy prestigiosa editorial The New Press.

La moraleja de este relato es que el principio autónomo, es decir, el que encarnan figuras como Chitarroni o Schiffrin, se ha escurrido del dominio de la industria editorial transnacional no para desaparecer sino para refugiarse en proyectos de reducido alcance local, sin mayor repercusión, pero que, sin embargo, les permiten sostener y promover un concepto de literatura aún definido por (sus) valores estéticos. La bestia equilátera, por supuesto, no está sola. Es parte de la hoy frondosa trama de las llamadas editoriales independientes ${ }^{5}$ que fue floreciendo en América Latina desde mediados de los años 90 en adelante. Desde ya y por lo pronto, una respuesta local al proyecto de expansión global de la gran industria cultural. De acá es posible extraer que estas editoriales independientes y la producción de literatura a nivel local -la que se lleva a cabo con escasa o ninguna mediación de agentes, scouts y gerentes de ventas- es el territorio donde aún hoy se pueden cultivar proyectos literarios más comprometidos con la experimentación formal que con el potencial de ventas. Esto, como en el caso de la literatura a escala mundial, se puede explicar por razones muy simples: los escritores, particularmente en América Latina, buscaron crear, desde los años 90 en adelante, canales de comunicación directa con su público, esto es, las editoriales independientes; se deshicieron, así, de la mediación que produce valor agregado a nivel internacional. Las editoriales independientes suelen no pagar derechos de ningún tipo y muchas veces no producen más ganancias que las necesarias para cubrir costos de impresión. Así, sin que se lo hayan propuesto, los conglomerados transnacionales, al colonizar los sistemas de edición nacionales e intentar imponerles su lógica a los campos respectivos, han favorecido el desarrollo de proyectos editoriales contrahegemónicos, más o menos disidentes, donde el valor literario, en su concepción occidental moderna o en versiones más críticas, todavía puede ser un principio dinamizador.

Recordemos, para concluir, otro caso. El escritor argentino Pablo Katchadjian recientemente ha recibido visibilidad mediática debido a una causa judicial iniciada por María Kodama, la viuda de Jorge Luis Borges. Katchadjian había "engordado" "El Aleph”, de Borges, es decir que, al texto original, él le había agregado palabras, líneas y pasajes. Mientras que Kodama -con respaldo de Emecé/Planeta y el agente Andrew Wylie- lo acusaba de plagio -y esto, naturalmente, también es expresión del principio heterónomo-, Katchadjian se defendía con el argumento

5 Voy a examinar las complejidades y la pertinencia del término "independientes" en el capítulo IV. Por el momento, lo voy a usar sin mayor distinción para referirme a editoriales que se resisten total o parcialmente a reproducir la lógica de gestión de los grandes multimedios. 
de la experimentación literaria -o, lo que para el caso es lo mismo, el de la autonomía-. Su texto -sostenía- no respondía a un proyecto comercial, sino a uno literario. Y de hecho la evidencia que en algún momento parecía que iba a decidir la contienda a su favor fue que de El Aleph engordado (2009) no habían salido más que 250 ejemplares y que la mayoría había sido regalada. ¿Cuál fue la editorial? Por supuesto ninguna perteneciente a los conglomerados transnacionales, sino la Imprenta Argentina de Poesía del propio Katchadjian. Una editorial vale agregar- dedicada exclusivamente a proyectos experimentales o, lo que es lo mismo, guiada por las premisas más radicales, y utópicas, de la autonomía literaria. También, naturalmente, una editorial con uno de los catálogos más respetados por la zona con mayor acumulación de capital simbólico del campo literario nacional. 